\title{
Belleville, Charentay, Saint-Georges-de-Reneins
}

Jean-Claude Béal

URL : http://journals.openedition.org/adlfi/7169

ISSN : 2114-0502

Éditeur

Ministère de la culture

Référence électronique

Jean-Claude Béal, «Belleville, Charentay, Saint-Georges-de-Reneins », ADLFI. Archéologie de la FranceInformations [En ligne], Rhône-Alpes, mis en ligne le 01 mars 2007, consulté le 19 avril 2019. URL:

http://journals.openedition.org/adlfi/7169

Ce document a été généré automatiquement le 19 avril 2019

(c) Ministère de la Culture et de la Communication, CNRS 


\title{
Belleville, Charentay, Saint-Georges- de-Reneins
}

\author{
Jean-Claude Béal
}

Identifiant de l'opération archéologique : 229582

Date de l'opération : 2007 (PI)

1 La communauté de communes Beaujolais - Vauxonne envisage, à la jonction des trois territoires de Belleville, Charentay et Saint-Georges-de-Reneins, la création d'un «Technoparc » concernant potentiellement plusieurs centaines d'hectares : l'extension et la localisation d'une partie du projet (le " parc nord ») sont définies, celles du " parc sud » sont encore en débat.

2 Une partie de ces terrains avaient déjà fait l'objet antérieurement des prospections de l'équipe de Ludna, dans le cadre de sa réflexion sur le territoire de l'agglomération antique; elles ont été complétées en août 2007, même si le couvert végétal n'était pas alors parfaitement favorable à cette activité.

3 Aucun site n'a été reconnu dans le "parc nord». Dans le "parc sud», où nous connaissions déjà quelques sites d'extension médiocre, la prospection de 2007 n'a pas ajouté d'éléments nouveaux.

4 BEAL Jean-Claude 
INDEX

Index géographique : Rhône-Alpes, Rhône (69), Belleville, Charentay, Saint-Georges-de-Reneins operation Prospection inventaire (PI)

AUTEURS

JEAN-CLAUDE BÉAL

Ens. Sup. 